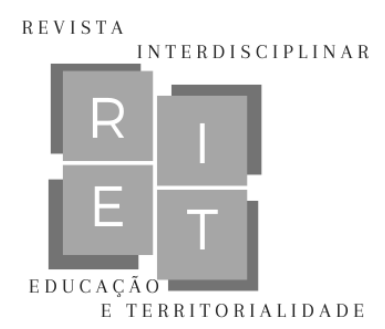

\title{
A escolarização pública e o imprevisto mais do que previsto
}

\author{
Public schooling and the imprevision more than predicted
}

\begin{abstract}
Escuela pública y la imprevisión más que prevista
Fernando Seffner

Programa de Pós-Graduação em Educação, Universidade Federal do Rio Grande do Sul (UFRGS) Porto Alegre, Rio Grande do Sul, Brasil E-mail: fernandoseffner@gmail.com ORCID: http://orcid.org/0000-0002-4580-6652
\end{abstract}

\begin{abstract}
Resumo: O artigo analisa alguns impactos da pandemia de COVID 19 no campo educacional público brasileiro, utilizando para isso informações extraídas de acervo de dados coletados pelo autor ao longo do período março 2020 a março 2021. O acervo reúne tanto informes gerais sobre a pandemia quanto, em especial, notícias que mostram os efeitos do prolongado período de isolamento sobre a escola e os processos de escolarização, e foi organizado na forma de linha de tempo com coleta diária. Analisam-se alguns discursos em torno da alternativa de $\mathrm{EaD}$, do ensino híbrido, do retorno às aulas presenciais ou manutenção das escolas fechadas. Discutem-se os impactos da pandemia e do avanço das tecnologias de educação online no cenário de desigualdade em termos de acesso a uma educação de qualidade no Brasil.
\end{abstract}

Palavras-chave: Educação pública. COVID 19. Desigualdade.

Abstract: The article analyzes some of the impacts of the COVID 19 pandemic in the Brazilian public educational field, using information extracted from a collection of data collected by the author over the period March 2020 to March 2021. The collection gathers both general information about the pandemic and, in particular, news that shows the effects of the prolonged period of pandemic on the school and the schooling processes, in a timeline mode daily. Some speeches about the alternative of distance education, hybrid teaching, the return to face-to-face classes or the maintenance of closed schools are analyzed. The impacts of the pandemic and the advancement of online education technologies in the context of inequality in terms of access to quality education in Brazil are discussed.abstract deve estar em Times New Roman, tamanho 12 (até 250 palavras).

Keywords: Public education. COVID 19. Inequality.

Resumen: El artículo analiza algunos de los impactos de la pandemia COVID 19 en el campo de la educación pública brasileña, utilizando información extraída de una colección de datos recopilados por el autor durante el período de marzo de 2020 a marzo de 2021. La colección recopila información general sobre la pandemia y, en particular, noticias que muestren los efectos del prolongado período de pandemia en la escuela y los procesos de escolarización, a modo de una línea del tempo diaria. Se analizan algunos discursos sobre la

RIET-ISSN 2676-0355, Dourados, v. 2, n. 2, p. 38 a 63, jan./jun., 2021. 


\section{A escolarização pública e o imprevisto mais do que previsto}

alternativa de la educación a distancia, la enseñanza híbrida, el regreso a las clases presenciales o el mantenimiento de escuelas cerradas. Se discuten los impactos de la pandemia y el avance de las tecnologías de educación en línea en el contexto de la desigualdad en términos de acceso a una educación de calidad en Brasil.resumo deve estar em Times New Roman, tamanho 12 (até 250 palavras).

Palabras Clave: Educacion publica. COVID 19. Desigualdad.

Data de recebimento: 13/04/2021

Data de aprovação: 10/06/2021

DOI: $10.30612 /$ riet.v\%vi\%i.14475

\section{Cultura escolar, saudade e sentimento de exclusão: a rima triste}

Este artigo é fruto de reflexões em torno de parcela de acervo pessoal, organizado em coleta sistemática de dados acerca da pandemia, na forma de linha de tempo e de focos temáticos, iniciada em março de 2020, logo quando da interrupção das aulas ${ }^{1}$. As fontes de coleta dos dados que compuseram o acervo são todas mídias online, e se dividem entre quatro grandes jornais brasileiros ${ }^{2}$, dois jornais em língua portuguesa que contemplam grande quantidade de matérias acerca da América Latina e da Europa ${ }^{3}$; dois jornais que coletam matérias em outros jornais por focos de interesse e produzem matérias próprias, bem como textos opinativos ${ }^{4}$; duas mídias online na forma de revistas de opinião com edição mensal e informativo diário ${ }^{5}$; uma revista com notícias prioritárias acerca da Argentina e cobertura importante de países da América do Sul ${ }^{6}$; dois repositórios do mapa epidemiológico global diário da COVID 19, com estatísticas e artigos analíticos ${ }^{7}$; três repositórios de dados e artigos analíticos sob responsabilidade da UNESCO, e que detalharam a situação escolar na América Latina, no mundo e no ensino superior, mostrando estatísticas do abre e fecha das escolas e das instituições de ensino superior, bem como publicando relatórios periódicos

\footnotetext{
${ }^{1}$ Em 2020 tivemos apenas uma semana e meia de aulas presenciais na UFRGS. Através da Portaria n 2286 de 17/03/2020 da Reitoria as aulas em todos os níveis foram suspensas. Disponível em: http://www.ufrgs.br/ufrgs/noticias/reitoria-institui-portarias-que-regulam-atividades-durante-periodo-desuspensao-de-aulas Numerosas outras portarias foram prolongando a suspensão, enquanto se definia o que fazer. Em 18 de agosto de 2020 as aulas do primeiro semestre letivo de 2020 foram retomadas, na modalidade Ensino Remoto Emergencial (ERE). Até a data em que escrevo esse artigo, todas as atividades ocorrem em regime remoto na UFRGS, sem previsão definida de retorno ao modo presencial.

2 São eles https://g1.globo.com/; https://gauchazh.clicrbs.com.br/; https://www.folha.uol.com.br/; https://www.correiobraziliense.com.br/. Vale dizer que mesmo para não assinantes os jornais abriram de modo livre um conjunto de notícias diárias acerca da COVID 19, o que possibilitou a coleta.

${ }^{3}$ Trata-se de https://brasil.elpais.com/ e de https://www.bbc.com/portuguese

4 Trata-se de www.nexojornal.com.br e https://www.canalmeio.com.br. Vale dizer que esses dois meios de comunicação dispõem de canais de YouTube e produção de podcasts, que foram consultados.

${ }^{5}$ São elas https://piaui.folha.uol.com.br/ e https://diplomatique.org.br/ Vale lembrar que essas duas mídias, à semelhança de outras, franquearam acesso gratuito a matérias acerca da COVID 19.

${ }^{6}$ Trata-se de https://www.pagina12.com.ar

${ }^{7}$ Trata-se de https://www.worldometers.info/coronavirus/ e https://coronavirus.jhu.edu/
}

RIET-ISSN 2676-0355, Dourados, v. 2, n. 2, p. 38 a 63, jan./jun., 2021. 


\section{A escolarização pública e o imprevisto mais do que previsto}

acerca dos impactos da pandemia na situação educacional mundial ${ }^{8}$; um site mantido por fundação internacional dedicado à divulgação de estatísticas e dados acerca de grande conjunto de temas em âmbito global, e que publicou matérias estabelecendo conexões entre seus bancos de dados e o impacto da COVID 19 em várias áreas sociais, econômicas e populacionais ${ }^{9}$; três repositórios dedicados especificamente ao acompanhamento da situação da COVID 19 no Brasil, dois deles mantidos por instituições acadêmicas e o terceiro mantido por consórcio de secretários de saúde dos estados ${ }^{10}$; e um canal do YouTube de reconhecido biólogo brasileiro, que se tornou grande comunicador científico no contexto da pandemia ${ }^{11}$.

O interesse inicial na recolha de material foi difuso. Deu-se um tanto pelo hábito colecionista de historiador, que viu ali indícios de uma interrupção no tempo ordinário das coisas, e resolveu guardar alguns materiais a cada dia. Em seguida, passei a tomar notas e registrar impressões em um diário de campo, sem uma noção exata do uso futuro que aquilo poderia ter. O impulso do registro também se deveu ao fato de ser professor, e de História. Como professor, percebi que o grupo de alunos e alunas da disciplina de estágio docente tinha que "se manter ocupado" enquanto as aulas estavam interrompidas. Sem saber direito o que fazer, sem ter ideia do tempo que a interrupção iria durar, e sem querer deixar alunos e alunas "sem nada para fazer", lhes dei a tarefa de comentarem alguns dos registros que eu coletava. Tal foi feito na forma de linha de tempo, usando software gratuito disponível na web ${ }^{12}$, e comecei eu a fazer o mesmo. Em menos de três semanas de aulas interrompidas, a tarefa se estruturou, com o uso do ambiente Moodle ${ }^{13}$, e com a definição de algumas fontes de consulta regulares para captar notícias da pandemia, que passou a ser um tema dominante em todas as mídias.

A coleta diária de dados envolveu notícias, estatísticas, artigos de análise da progressão da pandemia, editoriais de jornais, informes epidemiológicos assinados por gestores ou cientistas, atos do poder público, manifestações contrárias ou favoráveis às

\footnotetext{
8 Trata-se de https://es.unesco.org/fieldoffice/santiago/covid-19-education-alc; https://es.unesco.org/covid19/educationresponse e https://www.iesalc.unesco.org/

${ }^{9}$ Trata-se de https://ourworldindata.org/

10 Trata-se de https://www.ufrgs.br/redecovid19humanidades/index.php/br; https://redecovida.org/ e https://www.conass.org.br/painelconasscovid19/

11 Trata-se do canal https://www.youtube.com/channel/UCST1OTcyUmzvhQi6F81Fi5w do pesquisador e comunicador Atila Iamarino

12 Trata-se de https://www.timetoast.com/timelines/software-gratis-free

${ }^{13}$ Para isso, contei com a ajuda do monitor da disciplina, aluno do curso de História Bruno Erbe Constante, a quem agradeço o empenho, especialmente na organização do conjunto de dados quando este se tornou muito volumoso.
} 


\section{A escolarização pública e o imprevisto mais do que previsto}

medidas de distanciamento social, estímulo ou crítica ao uso de determinados medicamentos, novidades nos conhecimentos acerca dos modos de transmissão do vírus e de sua letalidade, reportagens dando conta da partidarização política das medidas de enfrentamento da COVID 19 no Brasil, textos contendo elementos de xenofobia em relação à origem e aos propósitos geopolíticos da doença, informes de autoridades e organismos internacionais, depoimentos de indivíduos ou famílias acerca dos modos de viver, trabalhar, estudar e manter a saúde mental e física durante o regime de distanciamento social, charges e memes, letras de rap, fotos de eventos, manchetes de jornais, propagandas, etc. Não havia uma questão de pesquisa visível. O esforço de registro da situação diária, feito por mim com a ajuda do monitor e dos alunos-estagiários, coletava de tudo um pouco, com o pensamento em ter subsídios para a elaboração de aulas de História, ou durante o período de ensino remoto, ou quando do retorno ao modo presencial, o que se imaginava não seria algo demorado. Parte do material efetivamente foi utilizada na produção de algumas sequências didáticas empregadas nos estágios docentes daquele primeiro semestre, ocorridos em modo remoto ${ }^{14}$. Focos temáticos foram se definindo com o andar da coleta. Pouco tempo após iniciada a montagem do acervo, diminuiu-se o volume de material de coleta diária, optando-se pela seleção de peças mais analíticas do contexto.

A ideia inicial era se debruçar sobre o conjunto coletado após o término da pandemia, buscando escrever artigos, em comportamento também típico de historiadores, que aguardam em geral que se estabeleça alguma distância temporal em relação ao fato acontecido, para então iniciar as análises. O contexto de escrita desse texto, entre fevereiro e março de 2021, não permite visualizar com clareza esse momento "após o final da pandemia". Pelo contrário, enquanto redijo o artigo ${ }^{15}$, o país bate diariamente recordes de mortes e de número de infectados, tornando-se epicentro mundial da pandemia. Também

\footnotetext{
${ }^{14}$ A disciplina que eu estava lecionando em 2020/1 era o Estágio Docente em História no Ensino Médio, e os estágios ocorreram em escolas públicas do Rio Grande do Sul, em regime remoto, com duplas de alunos trabalhando junto a uma professora ou professor regente em cada escola. $\mathrm{O}$ regime remoto possibilitou inserir estagiários em escolas tanto na região metropolitana de Porto Alegre, como habitualmente se fazia no regime presencial, quanto pelo interior do Estado, onde professores e professoras estavam mantendo ações pedagógicas regulares com suas classes de alunos e alunas. Agradeço aqui a disposição desses docentes em acolher os estagiários e estagiárias em momento tão conturbado e lhes prestar ajuda. Após a modalidade remota ser autorizada para estágios docentes pelo Conselho Nacional de Educação e pelo Ministério da Educação, ela foi regulamentada na UFRGS pela Portaria 5774 disponível em https://www.ufrgs.br/prograd/wpcontent/uploads/2020/11/portaria-de-altera\%C3\%A7\%C3\%A3o-do-calend\%C3\%A1rio-acad\%C3\%AAmico2020-5774-Reitor.pdf

${ }^{15}$ Entre fevereiro e março de 2021.
} 


\section{A escolarização pública e o imprevisto mais do que previsto}

estamos nos convertendo rapidamente em exemplo internacional de má gestão em saúde ${ }^{16}$, em vias de tornar-se uma verdadeira ameaça à saúde global. Tudo isso instiga a escrever e refletir. O momento é de ação, com toda certeza, mas também de reflexão, que ajuda a pensar estratégias. Ao longo do período de coleta, alguns dados já haviam sido desdobrados em conjuntos distintos. Aqui interessa tomar aqueles referentes ao campo da educação básica, para pensar aprendizados e desenhar ações.

De modo breve, apresento os contornos do acervo, que segue em processo de constituição, pois a coleta de dados não foi interrompida ${ }^{17}$. A linha de tempo geral apresenta 614 registros de todo tipo, o mais antigo datado de 18 de março de 2020, o último nesta contabilidade em 15 de março de 2021. Além disso, foram contabilizados 75 objetos de maior volume, nos quais se incluem livros (no formato ebook) lançados em geral de modo gratuito ou a um custo simbólico com conjuntos de artigos analíticos ao longo deste período de pandemia. Também considero objetos de maior volume os arquivos em formato PDF que são relatórios comentados acerca da epidemiologia da COVID 19 ou com conjuntos estatísticos sobre um foco temático específico, por exemplo, a situação de emprego, desemprego e mercado de trabalho em um dado momento da pandemia. O número de charges e memes coletados foi de 147, e esta coleta perdeu força ao longo do período, uma vez que esse tipo de material é de fácil localização via buscadores na web, e também porque há projetos de pesquisa focados na guarda destas produções ${ }^{18}$. Para o desenvolvimento do presente artigo foquei em conjuntos de dados específicos, que foram desde cedo agrupados em separado, e que são do campo do impacto da pandemia nas políticas públicas de educação. Foram construídos quatro conjuntos temáticos de informações em torno do grande tema da educação, ou do direito à educação, e suas vicissitudes no tempo da pandemia.

O primeiro conjunto está focado no tema do ensino à distância $(\mathrm{EaD})$, ou ensino remoto, educação online, educação remota, Ensino Remoto Emergencial (ERE) ou alguma outra denominação semelhante. Constituiu um acervo próprio desde que iniciou sua aparição nas mídias, e dele temos 76 registros, o mais antigo de 27 de março de 2020 . O tema do ensino híbrido é o interesse do segundo conjunto. Tal tema, ausente no início da pandemia,

\footnotetext{
${ }^{16} \mathrm{O}$ acompanhamento dos casos faço através de dois repositórios, https://ourworldindata.org/coronavirus-data e https://www.worldometers.info/coronavirus/ Acesso em 16 de março de 2021

17 A data em que fiz essa contabilidade foi 15 de março de 2021.

${ }^{18}$ Como exemplo brasileiro citamos o mais importante repositório de memes do país, o Museu de Memes, Universidade Federal Fluminense, em https://www.museudememes.com.br/ Acesso em 2 de março de 2021
}

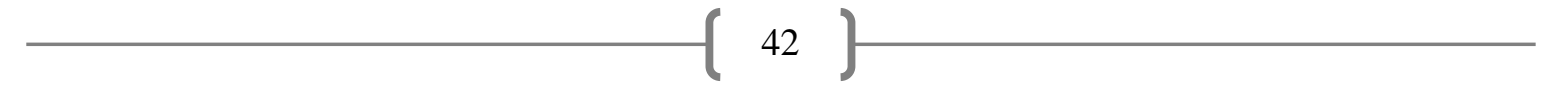

RIET-ISSN 2676-0355, Dourados, v. 2, n. 2, p. 38 a 63, jan./jun., 2021. 


\section{A escolarização pública e o imprevisto mais do que previsto}

veio ganhando força ao longo do debate que opôs - e ainda opõe no momento em que escrevo esse artigo - os que desejam manter as escolas fechadas e os que lutam pela sua reabertura, por vezes funcionando como solução conciliadora entre essas duas posições extremas. Desde o início arquivei notícias e manifestações sobre esse tópico em conjunto próprio, que conta com 38 registros, o primeiro deles datado de 29 de julho de 2020. A expressão Educação à Distância, com a sigla EaD, e suas variações acima assinaladas, era já conhecida no campo educacional e de ampla circulação na grande mídia e no portfólio de modalidades de cursos, em particular das instituições privadas de ensino superior. A expressão ensino híbrido, por vezes grafada como educação híbrida, era pouco conhecida no Brasil. Fez praticamente sua estreia nas grandes mídias durante a pandemia, e trouxe alguns elementos novos ao debate educacional. O terceiro conjunto reúne matérias sobre o tema "retorno às aulas" ou "volta às aulas”. Estas dizem respeito à polêmica em torno da manutenção de escolas fechadas ou de sua reabertura em um leque de modalidades diversas, e ali temos 104 registros, o mais antigo deles de 11 de agosto de 2020. São notícias, relatos de pesquisas de opinião, manifestações de autoridades, de pesquisadores e de instituições, editoriais de jornal, campanhas de sindicatos de professores, depoimentos de alunos, anotações de lives que debateram o tema, matérias sobre carreatas e movimentos sociais em torno do tema, notas técnicas de organismos internacionais, em particular aqueles das Nações Unidas, informes da situação em outros países, extratos de sentenças proferidas por juízes naquilo que se poderia chamar de vaivém de decisões judiciais contraditórias, etc.

O quarto conjunto se organiza em torno das conexões entre diversos tópicos que dialogam entre si: prejuízos ao rendimento escolar, desigualdade de acesso à educação, precariedade, violência contra crianças e jovens quando restritos ao ambiente doméstico, sugestões de estratégias para recuperar o que foi perdido no tempo da pandemia em termos educacionais, aprendizados acerca da importância da escolarização a partir dos desafios da pandemia. Esse quarto conjunto guarda conexões com os três anteriores, mas se destaca por agrupar dossiês de revistas acadêmicas científicas, dossiês de jornais e revistas de opinião, relatórios e estudos de organizações empresariais ou não governamentais em torno do tema do prejuízo escolar com a pandemia. São estudos de maior alcance teórico, e reportagens investigativas de maior fôlego, menos preocupadas em exatamente defender o retorno ou não às aulas presenciais, e mais em analisar efeitos de longo prazo derivados da situação de interrupção do cotidiano escolar, em particular para as famílias pobres e as minorias. Temos

RIET-ISSN 2676-0355, Dourados, v. 2, n. 2, p. 38 a 63, jan./jun., 2021. 


\section{A escolarização pública e o imprevisto mais do que previsto}

aqui 32 registros, o primeiro deles coletado em 30 de abril de 2020, com anotações a partir de um seminário web promovido pela UNESCO agência Santiago de Chile, cujo objetivo era:

Explorar las transformaciones, profundas y fundamentales, que son posibles para la organización futura de las sociedades, la política, la economía e incluso las culturas, e indagar sobre el papel que puede jugar la educación para facilitar dichas transformaciones. En razón de la coyuntura actual, el foco de la conversación estará puesto en las lecciones que se puede aprender, en general, de la crisis del COVID-19 y las acciones necesarias para proteger y transformar la educación en pos de la humanidad y del planeta. (UNESCO, 2020).

Já nesse primeiro registro temos a questão de aprender e transformar a educação por conta dos desafios postos pela pandemia. Nessa formulação, a vida na pandemia aparece vinculada à categoria da experiência, e podemos pensar que a humanidade está passando por uma experiência, e dela se podem tirar aprendizados. Esse é o tom da grande maioria dos registros desse quarto conjunto. A partir do exame dos materiais deste quarto conjunto é que se formulou o título deste artigo, a escolarização pública e o imprevisto mais do que previsto. Há um enunciado que percorre boa parte do material coletado referente ao campo da educação, e que permite concluir que o imprevisto - a pandemia - revelou desafios, problemas e questões já longamente sabidos e previstos no campo educacional, a maior parte deles ligados à situação de desigualdade estrutural das sociedades. Os desafios da desigualdade - social, econômica, cultural, de gênero e sexualidade, de geração, de local de moradia, de acesso a serviços e políticas públicas, etc. - não foram inventados pela pandemia, embora tenham com ela se magnificado. Dessa forma, o imprevisto em educação causado pela pandemia não traz exatamente situações inteiramente novas, mas modula de modo intensamente dramático situações já conhecidas.

Bem mais do que isso foi lido ou assistido ao longo do período, pois a pandemia dominou, e ainda domina, o noticiário e as conversas. O grande volume de notícias sobre o tema foi conduzindo a uma postura cautelosa acerca do que merecia arquivamento. Optei progressivamente pela coleta de materiais analíticos, na forma de reportagens investigativas, privilegiando conexões entre a pandemia e o campo educacional, bem como materiais com entrevistas a pesquisadores e autoridades públicas de gestão no campo educacional. Se soma, para a elaboração desse artigo, a consulta a um conjunto de excertos de falas e de anotações em diário de campo do que foi diretamente observado por mim em aulas online, nos

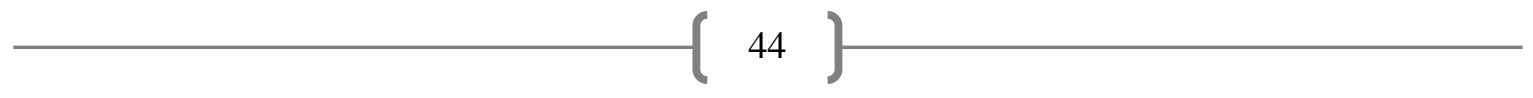

RIET- ISSN 2676-0355, Dourados, v. 2, n. 2, p. 38 a 63, jan./jun., 2021. 


\section{A escolarização pública e o imprevisto mais do que previsto}

momentos de supervisão de estágios de aulas de História, em escolas públicas da região metropolitana de Porto Alegre. Também me valho do que foi obtido em conversas e entrevistas com professores e professoras de História, na totalidade meus ex-alunos e exalunas das quase três décadas em que oriento estágios docentes de ensino de História, que se dispuseram a dialogar sobre o difícil momento pelo qual passavam. Com isso volto ao título desse primeiro tópico do artigo: a rima triste que fui me habituando a escutar ou ler, envolvendo conexões entre os elementos que constituem a cultura escolar e o cotidiano escolar, a sensação de saudade e o forte sentimento de exclusão. É possível saber da importância da escolarização quando ela se vê interrompida ou seriamente prejudicada de acontecer nos termos em que habitualmente vinha sendo praticada. A tese de fundo que anima esse artigo é a progressiva percepção que fui tendo de que a pandemia aprofundou desigualdades já existentes no cumprimento do direito à educação, e pode ter colaborado para reduzir o papel da escolarização à mera preparação para o exercício de funções no mercado de trabalho. Também se pode afirmar que o modo como foi se desenhando o debate sobre "o que fazer com a educação pública" tornou difícil seguir pensando nela como estratégia de acesso ao ensino superior pelas classes populares.

Com isso, há elementos concretos para pensar que, durante a pandemia, articularamse forças para interromper, ou no mínimo prejudicar, um processo que vinha se mostrando de relativo êxito na última década, viabilizando o prosseguimento dos estudos dos egressos da escola pública e das classes populares. A pandemia confrontou a produtividade de estratégias como sistemas de reserva de vagas para ingresso nas universidades e políticas públicas como ENEM, PROUNI, REUNI, FIES, SISU, bem como cursinhos populares para auxiliar minorias no bom desempenho no vestibular. Também aqui sou cauteloso, e me alinho com pesquisadoras que veem nessas estratégias avanços positivos, mas ainda longe de um efetivo processo de democratização de acesso ao ensino superior:

Entende-se, pois, que se trata de "certos avanços" na política de acesso, bem vindos em alguns aspectos, mas passíveis de crítica, considerando a insuficiência e as marcas da precarização implicadas. A base dessa reflexão está no entendimento de acesso que combine, articuladamente, ingresso, permanência e formação qualificada - ponto de vista que contribui para levantar questionamentos nem sempre evidenciados nas ações que configuram a educação superior. $\mathrm{O}$ acesso tende a ser visto e adotado pelas políticas públicas segundo aspectos isolados, a exemplo de considerar que um novo formato seletivo seja responsável pela sua democratização, ou que assim seja em relação a programas de assistência estudantil ou a expansão de vagas públicas. Essa inclinação faz persistir problemas

RIET-ISSN 2676-0355, Dourados, v. 2, n. 2, p. 38 a 63, jan./jun., 2021. 


\section{A escolarização pública e o imprevisto mais do que previsto}

causais e cria uma noção de resolução ilusória, que, afinal, cumpre uma função de acomodação às reformas. (SILVA \& VELOSO, 2012, p. 744).

Nos tópicos a seguir exploro algumas marcas encontradas em cada um dos quatro conjuntos de dados que articulam a pandemia com questões educacionais, em diálogo pontual com os excertos de falas e observação de cenas em aulas em sistema remoto. Tratase de aproveitamento um tanto lacônico do volume de dados, uma imersão em nível que reconheço raso, em acervo de águas tão profundas. Mas é o método para ir, aos poucos, realizando novas incursões. Se há algo que tenho neste momento certeza é que o período pandêmico está longe de terminar, e suas consequências mais longe ainda de se encerrarem. Sobre ele será necessário refletir muito. A tarefa aqui inicia, aproveitando pequena parte do acervo que venho coletando. Busco construir sentidos possíveis em meio a tantos acontecimentos que por vezes parecem indizíveis. Além desse tópico inicial do artigo, agrupo as demais reflexões em outros dois tópicos. Não há ao final o tradicional tópico “conclusões", pois não julgo ter elementos suficientes para tal. Proliferar questões talvez seja o ideal nesse momento inicial de exploração do material coletado.

\section{O ensino à distância e o ensino mais à distância ainda}

Definida em legislação específica, a "educação básica no Brasil é obrigatória e gratuita dos 4 (quatro) aos 17 (dezessete) anos de idade, assegurada inclusive sua oferta gratuita para todos os que a ela não tiveram acesso na idade própria" (BRASIL, 2009). Tratase de um longo período de vida, e como resultado do forte processo de inclusão escolar derivado da Constituição Federal de 1988 pode-se afirmar que praticamente não há mais como pensar a condição infantil e juvenil no Brasil sem ser em estreita relação com a escolarização, mesmo considerando as situações ainda existentes de interrupção ou abandono do percurso escolar. Ao longo desses marcos etários, a criança se transforma em jovem, e adquire graus de autonomia crescentes, também previstos em lei, como idade de consentimento, idade para trabalhar como aprendiz, idade para tornar-se votante, etc. Os conceitos de cultura escolar e cotidiano escolar dão conta dos múltiplos aspectos dessa jornada. A criança não ingressa simplesmente em uma escola aos quatro anos, ela passa a fazer parte de uma cultura, a cultura escolar (JULIA, 2001), e a viver um cotidiano com regras de espaço público, o cotidiano escolar (VICTORIO FILHO, 2017). Viver a cultura escolar - por vezes em escola de turno integral, onde se passa o dia inteiro e se fazem cinco

RIET-ISSN 2676-0355, Dourados, v. 2, n. 2, p. 38 a 63, jan./jun., 2021. 


\section{A escolarização pública e o imprevisto mais do que previsto}

refeições - envolve lidar com regras do espaço público, tradições, predomínio da cultura escrita e da argumentação racional, inserção em longo processo de alfabetização científica, diretrizes de convívio, aprendizado na forma de conhecimento disciplinar, construção de normas coletivas de relacionamento, estratégias de avaliação, modos de progressão ano a ano, estabelecimento de relações de afeto e amizade e, para grande parte de jovens, as primeiras experiências românticas. O cotidiano escolar é marcado pela interação com colegas que apresentam diversidade de arranjos familiares, de pertencimentos religiosos, de jeitos de viver gênero e orientação sexual, de raça, de ideário político, de projetos de futuro. Tudo isso em meio a um ordenamento das horas de estudo, dos intervalos, dos rituais, das idas ao banheiro, dos prazos.

Não existe condição de aprendizado escolar na Educação Básica desvinculado do entorno da cultura escolar e do cotidiano escolar ${ }^{19}$, e pensar sua condição virtual é um desafio posto pela pandemia. A exigência de distanciamento social, com fechamento das escolas, colocou na ordem do dia a opção de ensino remoto. $\mathrm{O}$ assunto tomou conta do noticiário desde meados de março de 2020, puxado inicialmente por instituições privadas ${ }^{20}$, e em seguida por redes públicas. Em final de abril o Conselho Nacional de Educação aprovou o primeiro dos muitos pareceres visando lidar com a situação de pandemia (BRASIL, CNE/CP, 2020), e tratando do que se chamou na legislação de "atividades não presenciais"21. A abordagem do tema pelo conjunto das mídias acompanhadas focou-se majoritariamente em estratégias didáticas "sem rosto" e até mesmo "sem autoria", ou seja, pacotes comprados de plataformas de ensino, sem uma autoria pessoal definida. A noção de "aula" separou-se da figura do "professor", e esta última quase desapareceu do noticiário, restando em muitos casos apenas menções a figura do professor como "facilitador" do acesso às aulas prontas, ou como alguém que precisava ser "preparado" para "entender as possibilidades dos meios

\footnotetext{
${ }^{19} \mathrm{O}$ mesmo pode-se dizer que vale para o ensino superior, analisando a importância da cultura do campus, e das interações que ali acontecem. Tal afirmação não implica dizer que a $\mathrm{EaD}$ seja uma versão degradada do ensino presencial, como logo adiante se discutirá, e muito menos que com ela não seja possível construir um entorno de cultura escolar.

${ }^{20}$ Este artigo trata exclusivamente da Educação Básica, mas vale salientar que as instituições privadas de ensino superior foram responsáveis por grande número de declarações e matérias em torno do tema, desde que a pandemia se instalou. De modo mais ágil do que as escolas particulares de Educação Básica, algumas universidades privadas retomaram as aulas em modalidade remota com intervalo de apenas dois dias de interrupção da modalidade presencial, o que se explica pela maior tradição nessa estratégia, bem como pelo perfil de alunado atendido.

${ }^{21} \mathrm{O}$ conjunto de pareceres sobre o tema pode ser visualizado na página web oficial do CNE em http://portal.mec.gov.br/pec-g/33371-cne-conselho-nacional-de-educacao/90771-covid-19 Acesso em 2 de março de 2021.
}

47

RIET-ISSN 2676-0355, Dourados, v. 2, n. 2, p. 38 a 63, jan./jun., 2021. 


\section{A escolarização pública e o imprevisto mais do que previsto}

digitais". Fica evidente nessas construções que o professor ou a professora são o lado "atrasado" da equação, frente ao lado "moderno", que são os meios e plataformas. A aula passou a ser uma entidade quase autônoma, que aparece sozinha nas frases. Proliferaram expressões como repositório de aulas, banco de aulas, aulas disponíveis, pacote de aulas, pacote de dados, kit de atividades, combo de estratégias didáticas, videoaulas prontas. Apareceram anúncios com títulos como "venda de pacotes com videoaulas e materiais"22. A ênfase do noticiário e das medidas tomadas foi direcionada para as tecnologias e os meios, com a proliferação de manchetes como "aulas pela TV", "aulas pelo celular", "aulas pela plataforma X ou Y", “o whatsapp como instrumento de aulas". Tecnologias e meios foram associados a empresas de porte mundial, em expressões como "utilizar o google class", "utilizar o google classroom", "vantagens do aplicativo educativo da Apple”, conferindo a essas estratégias educacionais um capital simbólico vigoroso, pelo poder das grandes marcas. O que está narrado acima me parece configurar o volume principal de matérias, mesmo aquelas de maior densidade, ao longo do primeiro semestre da pandemia. Tal afirmação não elimina o fato de que há menções e debates que buscaram problematizar as aulas em modalidade remota sem diminuir a importância da figura do professor ou da professora, mas estas foram minoritárias. A impressão que tenho, na leitura dos registros coletados, é que o momento inicial de enfrentamento da situação de fechamento das escolas foi dominado pelo discurso do ensino privado nas mídias, que buscou apresentar a EaD como alternativa eleita para atravessar a turbulência da COVID 19 sem prejuízos. As instituições privadas também buscaram se apresentar como já portadoras da expertise necessária, passando a imagem de uma transição sem grandes sobressaltos, e cobrando do governo federal a validação de suas estratégias, o que de fato foi progressivamente sendo concedido pela legislação.

Grande parte das matérias coletadas neste período inicial trata a EaD como substituto do ensino presencial, de modo direto, desconhecendo a literatura que enfatiza que EaD é modalidade específica, regulada em lei (BRASIL, 2017), e não a simples tradução para o ambiente online do que se faz presencialmente. O problema da forte desigualdade no acesso aos meios no Brasil marca presença desde o início das abordagens, e vai se acentuando conforme os números passam a mostrar o que se chamou por vezes de "apagão educacional"

22 Um exemplo dessa estratégia, no meio de muitos outros, pode ser conferido em https://www.clipescola.com/5-ideias-para-escola-crescer-na-pandemia/ coletado de 31 de agosto de 2020, acesso em 10 de dezembro de 2020

RIET-ISSN 2676-0355, Dourados, v. 2, n. 2, p. 38 a 63, jan./jun., 2021. 


\section{A escolarização pública e o imprevisto mais do que previsto}

ou "fosso existente no acesso aos meios digitais no Brasil". A desigualdade também vai ficando visível quando o noticiário mostra as redes públicas "paralisadas", enquanto o ensino privado está "em movimento". Progressivamente percebo o surgimento de matérias que dão conta do fato de que o que se está praticando, na urgência sanitária da pandemia, é um ensino remoto emergencial, ou uma modalidade emergencial de educação online, ou expressões semelhantes, que assinalam o caráter de excepcionalidade da adoção de ferramentas remotas. As afirmações iniciais da mídia, e mesmo de muitas autoridades de gestão educacional, em tom certamente aligeirado, que supunham a EaD como versão automática do ensino presencial, se tornam mais matizadas. A percepção de que aquilo que vem sendo praticado é na verdade uma versão de ensino remoto em situação de emergência se torna mais frequente na mídia. A ênfase nos meios e na tecnologia cede um pouco, e os elementos de interação social, cultura escolar e cotidiano escolar forçam passagem, e com eles a importância de professores e professoras. As comparações apressadas entre ensino presencial e $\mathrm{EaD}$, que situam em geral as entidades de classe de docentes a favor do primeiro, e os gestores públicos e proprietários de plataformas privadas a favor do segundo, sofrem críticas:

[...] problematizamos uma falsa dicotomia entre ensino presencial e EaD, ou ensino remoto, para sustentarmos que não é a forma de ensino - seja ele presencial ou a distância, ou remoto - que garante à proposta didáticopedagógica o efeito de troca, relação e construção de aprendizagens, mas, sim, os modelos teóricos conceituais que sustentam tais formas. (CHARCZUK, 2020, p. 3).

Percebo que inicialmente o debate na grande mídia se ocupou em mostrar que havia alternativas prontas para seguir estudando. $\mathrm{A} \mathrm{EaD} \mathrm{foi} \mathrm{eleita} \mathrm{de} \mathrm{modo} \mathrm{prioritário.} \mathrm{Talvez} \mathrm{por}$ ser categoria e sigla já de amplo conhecimento do grande público. Assegurava uma certa "segurança" para a travessia. Certamente tal atitude se deu pela suposição de que o período de exceção seria de pequena duração. Se ele é um período pequeno, um curativo pode ser ali colocado, a moda de um "band-aid", sem maiores problemas. Interessava mostrar no início que havia alternativas, em sintaxe já conhecida. A situação lembra um pouco a afirmação, que depois se generalizou no discurso presidencial, norte-americano e brasileiro, de que "a economia não pode parar", o que implica considerar a situação de emergência como de pouco potencial de dano, o que hoje em dia sabemos não ser verdadeiro. A EaD era ferramenta ali à disposição, para que se continuasse a "tocar" a educação sem rupturas

\section{9}

RIET-ISSN 2676-0355, Dourados, v. 2, n. 2, p. 38 a 63, jan./jun., 2021. 


\section{A escolarização pública e o imprevisto mais do que previsto}

maiores. A continuidade da situação de emergência, a recorrência do discurso do distanciamento social, o abre e fecha de estabelecimentos, os picos de contaminação cada vez mais frequentes, em contexto que passou a ser por vezes nominado como "novo normal", combinada com a multiplicação de vozes no debate educacional, forçou o ressurgimento de um elemento já amplamente comprovado pela literatura educacional:

[...] a escolarização repousa basicamente sobre as interações cotidianas entre os professores e alunos. Sem essas interações a escola não é nada mais do que uma imensa concha vazia (TARDIF \& LESSARD, 2009, p. 23).

Mais ainda, essa interação professores professoras alunos alunas tem função importante na conquista da autonomia intelectual dos jovens, que implica ampliação de horizontes em relação aos modos de ser família. Se vai à escola também porque “[...] os modos de socialização anteriores serão remodelados, abolidos, adaptados ou transformados em função dos dispositivos próprios do trabalho dos professores na escola" (TARDIF \& LESSARD, 2009, p. 23). Manter crianças e jovens por tempo indefinido em casa, mesmo com bom acesso a plataformas digitais, passou a ser criticado, e ingressaram no debate vozes médicas:

Qual o impacto da paralisação das escolas para as crianças?

FAUSTO CARVALHO ${ }^{23}$ : O impacto é brutal. A sociedade de pediatria fez um documento com o Conselho Regional de Medicina pedindo a retomada das aulas. A gente tem vários poréns. Tem a questão nutricional, de crianças em casa comendo pior, de criança que a única refeição nutricionalmente equilibrada era servida na escola e que não está tendo mais essa oportunidade. Tem a questão da convivência social. As crianças estão sem os amigos, sem contato presencial. Tem o dano de perda de vínculos, porque a criança precisa fazer um vínculo com o professor para ter o aprendizado legal, e o distanciamento pela internet prejudica isso. Tem a questão das atividades físicas, porque a escola é o lugar onde as crianças mais fazem atividade. Hoje, em casa, as atrações são todas eletrônicas, com videogame, computador. Há uma tendência da criança ficar mais sedentária. Há vários prejuízos ${ }^{24}$.

\footnotetext{
${ }^{23}$ Fausto Flor Carvalho é chefe do Departamento de Saúde Escolar da Sociedade de Pediatria de São Paulo.

24 Dossiê NEXO EDUCAÇÃO, veiculado em 6 de dezembro de 2020. Disponível em https://www.nexojornal.com.br/expresso/2020/12/06/Quais-as-press\%C3\%B5es-pela-volta-\%C3\%A0saulas-presenciais-no-

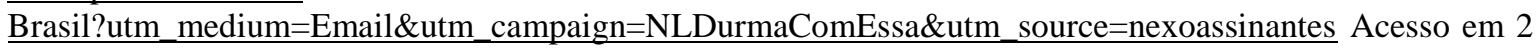
de março de 2021
}

RIET-ISSN 2676-0355, Dourados, v. 2, n. 2, p. 38 a 63, jan./jun., 2021. 


\section{A escolarização pública e o imprevisto mais do que previsto}

No excerto acima, a escola é apresentada em sintonia com os dois conceitos que escolhi como guias neste artigo: cultura escolar e cotidiano escolar. Embora não citados diretamente, os elementos que os caracterizam estão listados, não apenas no excerto, mas na totalidade de matérias que coletamos com as falas médicas. A escola que passa a fazer falta na vida das crianças e jovens é uma escola com volume sensivelmente maior de atributos. A importância da vida escolar se conecta com outros elementos da vida das culturas juvenis, inclusive regimes alimentares. A questão da convivência social aparece na totalidade das matérias coletadas em que médicos, psicólogos e psiquiatras são entrevistados. A EaD, sigla e estratégia utilizada fortemente no início do debate acerca das alternativas de enfrentamento à necessidade de distanciamento social, começa a se mostrar duplamente problemática. Primeiro, porque não permite a adequada continuidade da inserção de crianças e jovens na cultura escolar e no cotidiano escolar. Segundo, porque a crônica situação de desigualdade no Brasil não a permite alcançar grande parcela do alunado. Mas o debate que permitiria mostrar que é possível envolver crianças e jovens com o uso de ferramentas digitais com a cultura escolar e o cotidiano escolar é pobre. Ele esbarra na desigualdade de acesso, narrada em muitos depoimentos:

"O único que conseguiu acessar a plataforma foi o meu filho mais velho, de 15 anos. Nunca foi fácil, cheguei a pedir dinheiro emprestado para botar crédito no celular para ele acessar. Mas ele não entendia as matérias, e os professores não conseguiam explicar de longe. No fim ele disse que se sentia fraco, que não aprendia e queria desistir". O relato é da diarista Genesi Flores, do Quilombo da Família Flores, em Porto Alegre. Como ela, milhares de famílias cujas crianças estão matriculadas na rede pública foram desafiadas um ano atrás a lidar com os filhos fora da escola. Nas periferias da Capital, somam-se ainda problemas mais urgentes, como a falta de alimentação e condições básicas de higiene - nessa realidade, acesso à internet é luxo. (LIMA, 2021).

Sem condições de acesso a conexão web de qualidade, boa parte das intenções de boa escolaridade se perde. Um outro conjunto de precariedades da escola pública brasileira, já conhecido de longa data, passa a habitar o noticiário, a indicar velhos e novos problemas convivendo lado a lado, e são feitos dossiês ou reportagens investigativas. Informações já sabidas de muito tempo cruzam com decisões de hoje, como mostram os dois excertos abaixo, de matérias com diferença de dois dias:

Cresce número de escolas públicas sem banheiro e internet banda larga; 35,8 mil não têm coleta de esgoto. Dados são do Censo Escolar 2020,

RIET-ISSN 2676-0355, Dourados, v. 2, n. 2, p. 38 a 63, jan./jun., 2021. 
coletados em março do ano passado. Eles indicam que escolas já enfrentavam déficit de estruturas essenciais para a reabertura durante a pandemia. O número de escolas públicas que não têm banheiro e internet de banda larga cresceu entre 2019 e 2020, de acordo com o Censo Escolar da Educação Básica, do Ministério da Educação (MEC). Os dados foram coletados em março do ano passado. Eles indicam que as escolas já estavam com déficit de estruturas essenciais para a reabertura durante a pandemia e, caso não tenham sido feitas mudanças, podem ser um entrave para estudantes e professores retomarem as salas de aula. Em 2019, 3,5 mil escolas públicas não tinham banheiros, o que representava $2,4 \%$ do total. Em 2020, aumentou para 4,3 mil, 3,2\% do total. A internet banda larga não chegava a 15 mil escolas urbanas em 2019 (18,1\%), e cresceu para 17,2 mil (20,5\%) em 2020. Além disso, 35,8 mil escolas seguem sem coleta de esgoto, $26,6 \%$ do total. Antes, eram 36,6 mil $(27,1 \%){ }^{25}$

Bolsonaro veta integralmente projeto que assegura internet grátis a alunos e professores da rede pública. Presidente justificou que a 'medida dificulta o cumprimento da meta fiscal e da Regra de Ouro'. O presidente Jair Bolsonaro vetou integralmente o projeto que buscava assegurar internet grátis a alunos e professores da educação na rede básica. [...] O Senado aprovou a matéria em fevereiro. A proposta já havia sido aprovada pela Câmara em dezembro de 2020. O texto prevê que a União repassará $\mathrm{R} \$ 3,5$ bilhões aos estados e ao Distrito Federal para que os gestores locais adotem as medidas necessárias, incluindo a compra de planos de internet móvel e de tablets para professores e alunos. Pelo texto, os recursos iriam beneficiar: a) alunos das redes públicas de estados e municípios cujas famílias estejam inscritas no Cadastro Único para Programas Sociais do Governo Federal (CadÚnico); b) estudantes matriculados nas escolas das comunidades indígenas e quilombolas; c) professores da educação básica das redes públicas de ensino dos estados e municípios. O texto também previa que os recursos deveriam ser usados para a contratação de internet móvel, a fim de permitir que alunos e professores acompanhem atividades pedagógicas não presenciais. A prioridade era para alunos do ensino médio, do ensino fundamental, professores do ensino médio e professores do ensino fundamental, nessa ordem. O presidente justificou que a "medida encontra óbice jurídico por não apresentar a estimativa do respectivo impacto orçamentário e financeiro, e aumenta a alta rigidez do orçamento, o que dificulta o cumprimento da meta fiscal e da Regra de Ouro". ${ }^{26}$

\footnotetext{
${ }^{25}$ Reportagem investigativa feita a partir dos dados do Censo Escolar 2020, publicada em 21 de março de 2021, disponível em https://g1.globo.com/educacao/volta-as-aulas/noticia/2021/03/21/cresce-numero-de-escolaspublicas-sem-banheiro-e-internet-banda-larga-coleta-de-esgoto-nao-chega-a-358-mil-predios-escolares.ghtml Acesso na mesma data de publicação. Tal reportagem é a mais completa dentre numerosas outras, com dados do mesmo conjunto estatístico ou de pesquisas menos abrangentes, dando conta da mesma situação.

${ }^{26}$ A atitude da presidência da República vem na esteira de outros benefícios que foram cogitados para os sistemas de ensino, e terminaram cancelados ou consideravelmente diminuídos em volume de recursos. Reportagem publicada em 19 de março de 2021, disponível em https://g1.globo.com/politica/noticia/2021/03/19/bolsonaro-veta-integralmente-projeto-que-assegura-internetgratis-a-alunos-e-professores-da-rede-publica.ghtml Acesso na mesma data.
}

RIET-ISSN 2676-0355, Dourados, v. 2, n. 2, p. 38 a 63, jan./jun., 2021. 


\section{A escolarização pública e o imprevisto mais do que previsto}

Velhos problemas que persistem, atualização dos velhos problemas em contexto contemporâneo, aparecimento de novos problemas, falta de vontade política para resolução dos problemas. A saudade da cultura escolar e do cotidiano escolar, expressa em reportagens da mídia, indica que, conforme debatem CHRISPINO \& CHRISPINO (2002), a tarefa escolar de demarcar certa territorialidade, certo paradigma de autoridade, de regras, de tempos e limites, é indicativo de inclusão no espaço público. Sua ausência reforça a sensação de exclusão, de ter sido deixado para trás, conforme os excertos das conversas com alunos do Ensino Médio e com docentes de escolas públicas com quem tive oportunidade de dialogar, quando da supervisão dos estágios docentes em regime remoto apontam:

Eu não pensava que eu gostava tanto do colégio. Eu sempre achei que gostava só da minha turma, agora sinto falta de tudo, até de acordar cedo para ir à aula, até das broncas. Eu me sinto meio fora do mundo, o mundo tá passando, e eu estou ficando aqui em casa. (Aluno autodeclarado negro, 15 anos, escola pública município da região metropolitana de Porto Alegre, Ensino Médio)

Eu vejo na televisão que tem escola voltando, tem guri aqui no bairro que já voltou, e lá no meu colégio não volta, lá não tem condição, nem álcool gel, tudo quebrado, a minha mãe fica nervosa, eu fico nervoso, fica tudo mundo nervoso lá em casa. (Aluna autodeclarada branca, escola pública de Porto Alegre, Ensino Fundamental)

A saudade que eu sinto da sala dos professores não tem tamanho. Nem sei explicar, eram só 20 minutos no recreio, tudo corrido, conversa, café, pega material, comenta com colegas, e eu lembro disso todos os dias. (Professora autodeclarada branca, 38 anos, escola pública da região metropolitana de Porto Alegre, docência no Ensino Fundamental ${ }^{27}$

O contexto faz lembrar o quão distante estamos da concepção fundante da escola na modernidade, animada pelos ideais de progresso, marcha ascendente na História, desenvolvimento de uma sociedade letrada e ilustrada, conhecimento posto à disposição da geração de uma sociedade justa para todos e todas, conforme debatido em Sacristan (2001, p. 21). Não se trata de concordar com o retorno a esse modelo de escola. Mas confesso que chego a ter saudades de tais declarações de intenção, que sabemos bem não vingaram, mas que no momento em que digito esse artigo foram substituídas por estratégias explícitas de exclusão e produção de mais desigualdade no campo educacional.

${ }^{27}$ Diário de campo das observações de aula e diálogos com docentes, ano 2020, anotações pessoais.

\section{3}

RIET-ISSN 2676-0355, Dourados, v. 2, n. 2, p. 38 a 63, jan./jun., 2021. 


\section{A escolarização pública e o imprevisto mais do que previsto}

\section{Quem volta, quando volta, como volta e se é que volta}

$\mathrm{Na}$ linguagem que os gestores nos acostumaram na pandemia, reabrir ou não reabrir algum serviço ou estabelecimento depende de ele ser classificado como atividade essencial. A lista de atividades essenciais está o tempo todo sujeita a pressões políticas dos setores envolvidos e ao ideário partidário do gestor de plantão. O que confirma que, a despeito do enorme esforço de muitos grupos sociais conservadores hoje em dia para apresentar as ideologias como nefastas, e requerer sua ausência na tomada de decisões, elas estiveram presentes de modo vigoroso a cada passo das decisões. Para alguns as igrejas são atividades essenciais, por conta da necessidade de conforto espiritual na pandemia. Ou talvez porque no público de adeptos a elas esteja o maior número de eleitores de tal ou qual prefeito. Para outros, devem permanecer fechadas. Academias oscilaram entre serem essenciais ou não essenciais, por conta do bem-estar físico ou do perigo de contágio em ambiente fechado. $\mathrm{O}$ comércio de rua viveu - e ainda vive no momento em que escrevo esse artigo - um movimento pendular de abre e fecha. O debate por vezes oscilou entre abrir "grandes" estabelecimentos ou favorecer os "pequenos". Supermercados permaneceram abertos durante toda a pandemia, mas tiveram áreas de produtos não essenciais por vezes bloqueadas. O setor de turismo e hotelaria não obteve muito sucesso em se enquadrar na categoria de atividade essencial, mas mesmo assim foi autorizado a seguir funcionando, embora com possibilidade de acolhida menor de visitantes ou hóspedes. Bares e restaurantes oscilaram entre fechamentos, abertura com restrição de horários, permissão apenas para busca e retirada de encomendas ou sistema de delivery. Sugiro um exame atento aos decretos que listaram e argumentaram em torno das atividades permitidas e proibidas, onde temos de salões de beleza a agências bancárias. Tais decretos fornecem uma interessante visão do que, em nossa sociedade, pode ser considerado, e por quais motivos, como uma atividade "essencial”, e em que medida esse "essencial" é entendido, bem como o que se encaixa na rubrica "não essencial", e por conta de quais argumentações.

Parece haver consenso na sociedade de que a educação é uma das políticas públicas essenciais, mesmo em tempos de manifestações anticiência. Entretanto, os reiterados ataques à escola e aos processos de escolarização levantam dúvidas de que sejam elas sejam essenciais, no modo presencial como a conhecemos. Mas o debate em torno de seu funcionamento seguiu caminhos próprios, poucas vezes se misturando com as decisões gerais. Com o prolongamento das escolas fechadas, associado à precariedade de acesso, pela

RIET-ISSN 2676-0355, Dourados, v. 2, n. 2, p. 38 a 63, jan./jun., 2021. 


\section{A escolarização pública e o imprevisto mais do que previsto}

maior parte do alunado, a atividades em regime remoto, a imprensa passou a pautar o tema do retorno aulas presenciais com mais vigor. Dois elementos marcaram o conjunto de matérias coletadas no período que vai de meados do ano de 2020, quando já havia sinais claros de que a pandemia seria duradoura, até ao momento em que escrevo esse artigo. $\mathrm{O}$ primeiro é a completa ausência de uma coordenação nacional, a ser feita pelo Ministério da Educação, em torno da matéria. A Constituição Federal de 1988 prevê expressamente em seu artigo 211 o princípio do regime de colaboração nas políticas públicas de educação (BRASIL, 1988). Esse princípio, posteriormente regulado em diversas legislações específicas, indica que os entes federados devem organizar e gerir os sistemas de ensino em regime de colaboração, evitando conflitos e competição. A legislação reconhece a autonomia dos sistemas de ensino, mas a função desse princípio constitucional é estimular a pactuação entre os entes federados, em um país tão heterogêneo e de dimensões continentais como o Brasil. O que se viu foi o completo abandono desse princípio, e as matérias da grande imprensa sequer lembraram a quebra desse compromisso constitucional. Muitos editoriais criticaram a omissão do MEC, mas não apresentaram alternativas. As pressões políticas em cada estado e município derrubaram amplamente essa pretensão, e o MEC, seguindo a orientação praticada pela presidência da República, abriu mão de coordenar qualquer resposta nacional. Dessa forma, examinando apenas o caso do local onde vivo, a região metropolitana de Porto Alegre, tivemos todo tipo de situação, com escolas estaduais voltando a funcionar e distantes poucas quadras de escolas municipais, por vezes na mesma rua, que permaneciam fechadas. Em uma mesma família, um filho retornou à escola, e uma filha não.

A ausência de políticas coordenadas e colaborativas estimulou certa atitude de "cada um faz o que acha melhor". Isso leva ao segundo elemento que marcou o conjunto de matérias coletadas, muitas das quais permitindo conhecer a posição dos gestores: a ausência de uma discussão acerca do que implica, exatamente, reabrir uma escola. O que significa, exatamente, voltar às aulas? Como se volta? Como se organiza o espaço escolar para receber alunos e alunas, professores e professoras? Como se orientam as famílias nos procedimentos em relação a filhos e filhas que agora passam a ir à escola? Tais questões foram tratadas, na maior parte das vezes, com o uso de expressões que, de tanto citadas, se tornaram completamente esvaziadas, do tipo "seguindo os protocolos exigidos pela situação sanitária", ou então "cumprindo os requisitos do distanciamento social", ou, no mais das

RIET-ISSN 2676-0355, Dourados, v. 2, n. 2, p. 38 a 63, jan./jun., 2021. 


\section{A escolarização pública e o imprevisto mais do que previsto}

vezes, com a repetição infindável da frase "com o uso de máscaras e álcool gel”. Pouco se abordou a experiência de outros países, pouco se produziu em termos de protocolos objetivos, listando ações e equipamentos necessários, não tivemos a produção de cartilhas ou manuais indicando com clareza o que implicava a volta às aulas. $\mathrm{O}$ coroamento desse vazio de discussão veio na forma de exigência de um documento, assinado pelos pais de alunos e alunas, indicando que concordavam com o retorno de seus filhos e filhas às escolas, assumindo com isso a responsabilidade pela decisão. Em resumo, as autoridades não produziram diretivas claras do que implicava o retorno às aulas, nada informando acerca do transporte escolar, dos cuidados necessários quando do retorno para casa, do que cada aluno e aluna deveria fazer, etc. Ao não explicitar quase nada a respeito desse complexo problema do retorno das crianças e jovens às escolas, coroaram essa atitude com a exigência de um termo assinado pelas famílias autorizando seus filhos ao retorno. Ou seja, se isentando de quaisquer possíveis consequências do retorno de crianças e jovens às aulas. Dessa forma, o que podemos perceber é que a racionalidade neoliberal não opera no Brasil apenas na já conhecida direção do "estado mínimo". Entre nós se pratica também a construção de uma nova modalidade de ação estatal, desacompanhada de qualquer garantia de sua eficácia e segurança. $\mathrm{O}$ estado age, mas não oferece garantias. Não é de admirar que, em meio à ausência de tais garantias, o Brasil esteja entre os países do mundo que mais tempo permanecem sem uma definição de retorno às aulas, com evidente prejuízo em termos educacionais, especialmente para as populações mais empobrecidas ${ }^{28}$.

O embate entre grupos pela reabertura das escolas e aqueles que defendem que se mantenham fechadas mostrou contornos políticos que merecem comentário. Examinando os debates e votações no âmbito da Assembleia Legislativa do Rio Grande do Sul em meados de março de 2021, em torno de projeto enviado pelo Executivo Estadual que inseria a educação nas atividades essenciais, e pedia autorização para sua reabertura presencial imediata, tivemos votações que posicionaram como favoráveis e contrários grupos que apenas um mês antes estavam em posições opostas. O retorno das aulas presenciais, desejo do governo estadual, foi defendido e obteve maioria contando com votos de um grande

\footnotetext{
${ }^{28} \mathrm{O}$ acompanhamento detalhado da situação mundial, país a país, semana a semana, para saber o contingente de crianças e jovens na escola, e a situação das escolas (escolas fechadas, abertas parcialmente, abertas completamente, ensino híbrido, etc) pode ser feito consultando o World Bank Education COVID-19 School Closures Map em https://www.worldbank.org/en/data/interactive/2020/03/24/world-bank-education-andcovid-19 Acesso em 20 de março de 2021
} 


\section{A escolarização pública e o imprevisto mais do que previsto}

conjunto de deputados que não apenas apoiam a implantação do sistema de homeschooling, como também entre eles estava o próprio deputado que em fevereiro de 2021, ou seja, apenas um mês antes, havia logrado aprovar a constitucionalidade da matéria, e dar andamento ao Projeto de Lei (PL) 170/2019, que trata da educação doméstica, com o apoio da maioria da Comissão de Constituição e Justiça estadual. Na mão contrária, o bloco de deputados e deputadas que se opõe à aprovação da legislação de homeschooling votou pela manutenção das escolas fechadas até que o Estado do Rio Grande do Sul não estivesse mais no regime de bandeira preta do distanciamento controlado, que é o mais rigoroso. Em termos simples, os deputados que apoiaram e lograram aprovar a reabertura das escolas em modalidade presencial, considerando a educação escolar como atividade essencial, são os mesmos que, apenas um mês antes, defendiam a aprovação do homeschooling para todos os níveis e graus do ensino estadual. Temos aí uma mensagem embaralhada, aonde se fazem duas afirmações simultâneas que soam contraditórias: afirma-se que a educação pública, presencial e coletiva é atividade essencial, mas ao mesmo tempo que ela pode ser dada em casa, no formato que se vem cada vez mais chamando no Brasil de homeschooling. Tendo em vista o fato de que tais projetos foram levados à votação em plenário na Assembleia Legislativa do Rio Grande do Sul com diferença de menos de trinta dias, o flagrante de contradição ficou evidente ${ }^{29}$. Tal divisão partidária ficou óbvia também nas carreatas, acontecidas em algumas das principais cidades do Rio Grande do Sul em março de 2021, com grupos favoráveis ou contrários à reabertura das escolas, em que a divisão partidária acompanhou, de modo evidente, o que se viu no Estado no segundo turno da eleição presidencial de 2018, bem como na aprovação da possibilidade de homeschooling ou não. São justamente as famílias e os políticos que defendem a educação doméstica que mais desejam a reabertura das escolas, para que a vida volte ao normal. Na mão contrária, defensores da educação pública e contrários ao homeschooling estão juntos nesse momento pela manutenção das escolas fechadas. Volto ao comentário feito acima: não é de admirar que o Brasil esteja entre os países do mundo há mais tempo com escolas fechadas, dado o elevado grau de politização,

\footnotetext{
${ }^{29}$ Para saber da articulação em torno do projeto que desde 2019 tramita na Assembleia Legislativa do Rio Grande do Sul tratando do homeschooling e de seus desdobramentos em fevereiro de 2021, veja notícia oficial em http://www.al.rs.gov.br/agenciadenoticias/destaque/tabid/855/IDefault.aspx?IdMateria=319647, e para tomar contato com parte da polêmica em torno de projeto que prevê a aprovação da educação como atividade essencial e da possibilidade do retorno presencial obrigatório no Rio Grande do Sul votado em março de 2021 veja notícia em https://gauchazh.clicrbs.com.br/coronavirus-servico/noticia/2021/03/aprovado-projeto-quetorna-ensino-atividade-essencial-no-rs-mas-sem-obrigar-reabertura-de-escolasckmcjt08g00810198s2b2onut.html Acesso em 22 de março de 2021
}

RIET-ISSN 2676-0355, Dourados, v. 2, n. 2, p. 38 a 63, jan./jun., 2021. 


\section{A escolarização pública e o imprevisto mais do que previsto}

e partidarização, da matéria, combinado com a omissão da autoridade federal e a quase total ausência de diretrizes claras em torno do que significa reabrir escolas.

No debate entre definir quem vai retornar primeiro ao ensino presencial - se as crianças da educação infantil ou os que estão próximos de conclusão do Ensino Médio - bem como de que modo vai se dar o retorno - se com grupos escalonados da mesma série e alternando aulas presenciais e remotas ou se apenas com apoio presencial para aulas remotas - temos o grupo que pode não retornar tão cedo ao percurso da escolarização. No caso brasileiro, foi apenas com a Constituição Federal de 1988 e com legislações posteriores que a educação passou a trilhar o caminho da obrigatoriedade, com políticas públicas como o Programa Bolsa Família e os programas de transporte escolar e merenda escolar assegurando a permanência na escola. Esse é um percurso recente, e ainda não consolidado, embora já com alguns ganhos evidentes, inclusive com acesso ao ensino superior de jovens originários das classes mais pobres. A pandemia teve o efeito de sacudir esse quadro pouco consolidado, e afastar alguns jovens da escola, de modo que poderá ser temporário ou definitivo, a depender da oferta de políticas públicas de inclusão mais vigorosas no futuro. Há diversos elementos em jogo nesse cenário. Um deles é a quase vontade manifesta dos atuais governantes em não apostar na educação pública, e pouco se importar com a progressão nos estudos dos jovens oriundos das classes mais vulneráveis, seja vulnerabilidade derivada do marcador raça - esse é um governo decididamente contrário ao sistema de cotas - seja vulnerabilidade derivada de gênero - esse é um governo decididamente contrário ao postulado da equidade de gênero e fortemente opositor as demandas do movimento feminista - seja vulnerabilidade de classe - esse é um governo claramente adepto aos conceitos da racionalidade neoliberal, e cada sujeito é visto como um empresário de si mesmo, portanto responsável por tudo que lhe acontece no mundo do trabalho e dos ganhos salariais, não sendo adequado que se lhe forneçam benefícios ou incentivos financeiros, que poderiam causar acomodação ou preguiça no ethos empreendedor - seja vulnerabilidade derivada do campo da orientação sexual - esse é um governo completamente avesso as pautas do movimento LGBTQIA+ e que não reconhece que o Brasil seja país hostil a essas minorias sexuais.

Tomando o marcador geração, em conexão com possibilidades ou não de inserção no mercado de trabalho, temos dois conjuntos de dados que dialogam com um depoimento

RIET-ISSN 2676-0355, Dourados, v. 2, n. 2, p. 38 a 63, jan./jun., 2021. 
que colhemos. O primeiro conjunto de dados é oriundo do acompanhamento trimestral da PNAD Contínua do IBGE:

A taxa de desemprego de pessoas com 50 anos ou mais no Brasil chegou ao seu nível mais alto em 2020, quando ultrapassou $7 \%$ pela primeira vez desde 2012, quando começa a série histórica da Pnad Contínua, do Instituto Brasileiro de Geografia e Estatística (IBGE). Em um ano, do fim de 2019 até o fim de 2020, mais de 400 mil brasileiros nessa faixa etária caíram no desemprego. O movimento de alta no desemprego para essa idade nos últimos anos acompanha a piora registrada para as demais faixas etárias. No entanto, chama atenção que, proporcionalmente, o aumento da taxa de desemprego foi maior para o grupo de 50 anos ou mais [...] Para quem tem 50 anos ou mais, a taxa de desemprego saltou de $2,7 \%$ no último trimestre de 2012 para $7,2 \%$ no fim de $2020 .{ }^{30}$

Em sintonia com os dados acima, a mesma pesquisa mostra que os recrutadores de empresas buscam no mercado de trabalho substituir trabalhadores mais velhos por trabalhadores mais jovens, em particular na ocupação de postos que não exigem muita qualificação, requerem alguma disposição física, não envolvem grande expertise na escolarização, bem como prescindem de experiência anterior. Em um momento de crise financeira como vivemos, magnificada pela duração da pandemia, as famílias tiveram um incremento importante no endividamento. O filho, ou a filha, que estava estudando, por vezes em escola de turno integral, agora está em casa, com precário vínculo com a escola. $\mathrm{O}$ pai e a mãe, que trabalhavam, agora estão sem emprego, ou trabalhando menos do que gostariam. Colhemos, no diálogo com um aluno do Ensino Médio de escola pública da região metropolitana de Porto Alegre, depoimento de quem lida com essa situação:

O meu pai já tinha sido despedido bem antes da pandemia. Estava fazendo Uber, ele que nem gosta muito de dirigir, pois tem dor de coluna. Agora com a pandemia o movimento diminuiu no Uber. A minha mãe e a minha tia eram vendedoras em loja ali na Assis Brasil. Foram demitidas, porque as lojas andam fechadas e com pouca gente que vem comprar. Eu passava o dia no colégio, agora fico em casa. Não tem como, eu fui atrás de emprego, já estou fazendo entregas, comecei entregando máscaras que as vizinhas produziam, agora é comida, rancho do supermercado, vou pagar conta no banco para quem não pode sair de casa, pego o almoço no bar e levo para uma vizinha idosa todo meio dia, é o dia todo na rua. A escola ficou nessas horas de aula remota, mas quase acabou. (Rapaz autodeclarado branco, 15 anos, aluno do Ensino Médio).

30 A apresentação dos dados e o excerto citado acima estão disponíveis em https://www.bbc.com/portuguese/brasil56365723? utm source=NexoNL\&utm medium=Email\&utm campaign=OQEL Acesso em 23 de março de 2021

RIET-ISSN 2676-0355, Dourados, v. 2, n. 2, p. 38 a 63, jan./jun., 2021. 


\section{A escolarização pública e o imprevisto mais do que previsto}

Servir-se do percurso educacional para melhorar de vida não é algo percebido como muito eficaz por largas parcelas da população, especialmente as mais pobres, embora seja modelo cultuado pela classe média e largamente divulgado na mídia, com o mantra "estuda para ser alguém na vida”. Os números das pesquisas e relatórios produzidos pelo Instituto Mobilidade e Desenvolvimento Social (Imds), uma plataforma que utiliza informações de repositórios públicos e pesquisas acadêmicas, estabelecendo diálogo entre os dados nacionais e os indicadores internacionais de mobilidade social, confirmam essa percepção das classes vulneráveis:

Romper a barreira de acesso à educação é mais difícil no Brasil. Essa é a conclusão de um estudo Instituto Mobilidade e Desenvolvimento Social sobre desigualdade na educação em diversos países. Em cada dez brasileiros cujos pais não completaram o ensino médio, seis $(58,3 \%)$ também não irão concluí-lo. Entre as famílias $20 \%$ mais pobres, esse percentual salta para $80,8 \%$. Nos EUA, são $29,2 \%$. A falta de mobilidade educacional no Brasil é um dos fatores que perpetuam a desigualdade de renda no país. ${ }^{31}$

No Brasil, largar a escola para trabalhar é uma necessidade sempre presente no horizonte, mesmo com a melhoria dos modos de inclusão social legados pela Constituição Federal de 1988. A pandemia afetou a crença na capacidade de a escolarização modificar, para melhor, a situação dos mais pobres. Entre ganhos incertos no futuro derivados da permanência na escola, e ganhos reais no presente que possam fazer diferença na vida cotidiana de famílias que sofreram sensível empobrecimento, a opção por inserir-se no mercado de trabalho aparece como um tanto óbvia. O colchão de proteção social necessário para que famílias pobres mantenham filhos na escola sofreu erosão sensível nesse ano de pandemia, e as expectativas de recuperação da economia afetam projetos educacionais, que fazem do presente dos jovens momento de preparação para o futuro. Se o presente traz necessidades agudas, e exige atitudes imediatas de ganhos salariais, com isso se atropelam os planos de futuro. A educação pública sofre com isso, e se vê um tanto desprestigiada.

\section{Muitos finais e muitos começos}

31 O excerto é fruto de matéria que comenta dados do Imds, em https://www1.folha.uol.com.br/mercado/2021/03/no-brasil-chance-de-filho-repetir-baixa-escolaridade-dopai-e-o-dobro-dos-eua.shtml Acesso em 20 de março de 2021. O banco de dados com relatórios específicos por tema, educação entre eles, e suas conexões com mobilidade social, pode ser buscado em https://imdsbrasil.org/

60

RIET-ISSN 2676-0355, Dourados, v. 2, n. 2, p. 38 a 63, jan./jun., 2021. 


\section{A escolarização pública e o imprevisto mais do que previsto}

Concluo esse texto percorrendo novamente essa enorme quantidade de material juntado nesse pouco mais de um ano de pandemia. Corro os olhos mais pelos títulos e subtítulos, como uma pescaria de superfície. O volume de questões afetadas pela pandemia é enorme. Muita coisa tem gosto do que terminou. E muitas outras tem aspecto do que começa. O momento difícil de 2020, continuado em versão mais ansiosa e acelerada nesse início de 2021, permite perceber que se fala em surto de depressões; implosão de famílias; agudização da questão racial; pressões para mudanças em hábitos de consumo; muita conversa sobre a necessidade de um recomeço nas vidas e nos rumos de países e sociedades; preocupação com a alimentação equilibrada; medo pelo destino da Amazônia; temor e desejo por se aglomerar; frustração com o trabalho; angústia acerca do futuro das relações humanas; sensação de incerteza em relação ao futuro em geral; crença na ciência e ao mesmo tempo cultivo do apego a opiniões e crenças sem comprovação; dúvidas acerca de onde termina o espaço que necessito para viver e onde começa o espaço do outro; exaustão em relação aos regimes democráticos e representativos; vontade de mudar de lugar, ir da cidade ao campo, de um país a outro; etc.

No campo da educação certamente estamos dominados por uma sensação de que a pandemia acelerou desigualdades, e ao mesmo tempo acelerou a introdução de tecnologias de acesso remoto já existentes, agora um tanto massificadas. A direção desses dois processos pode se somar, a saber, tecnologias produzindo mais desigualdade, ou pode se contrapor, a saber, um uso das tecnologias que permita mais inclusão e menos desigualdade. Não há como prever, o jogo todo é de resultado incerto e sempre contingente. Com certeza o acesso às redes de wifi é, daqui para frente, algo da ordem dos direitos humanos de alunos e alunas, professores e professoras, e necessita ser regulado em políticas públicas. Ter um bom computador pessoal e dispor de uma boa rede de conexão não são mais luxos, são questões sociais e educacionais da esfera dos direitos básicos.

Mas o que mais parece ameaçar a função escolar é certa produção da ignorância, processo em marcha no país, que sofreu larga ampliação com a pandemia. A ignorância, sabemos bem, não é o que sobra no entorno da falta de conhecimento. A ignorância é ativamente construída a cada momento, por vezes celebrada de modo ruidoso, e ela tem funções políticas bem explícitas. Uma das modalidades mais fortes de sua expressão é a epidemia de opiniões acerca da doença e de seus tratamentos, sem qualquer conexão com o pensamento científico ou com as modalidades de debate entre pontos de vista, do ponto de

\section{1}

RIET-ISSN 2676-0355, Dourados, v. 2, n. 2, p. 38 a 63, jan./jun., 2021. 


\section{A escolarização pública e o imprevisto mais do que previsto}

vista racional. A função escolar se vê ameaçada, e em parte invalidada, por essa vaga de manifestações ao tipo "eu acredito que é assim", ou "essa é a minha opinião, e pronto". A produção da ignorância "também está presente na confusão sobre a epidemiologia social da covid-19 - com destaque para as formas que a pandemia afeta comunidades e populações distintas com base em classe, raça e etnia, gênero e outros marcadores de diferença social" (PARKER, 2021). Retomamos o título deste artigo, com a sensação de que fomos colhidos por um imprevisto mais do que previsto, que mistura necessidade de garantia de acesso a tecnologias e políticas públicas de enfrentamento da desigualdade educacional. Mas o fato dele ser mais do que previsto não lhe retirou o impacto de imprevisto, e de consequências duradouras para o campo educacional.

\section{Referências}

BRASIL. Anuário Brasileiro da Educação Básica. São Paulo: Moderna, 2018

BRASIL. Decreto $\mathrm{n}^{\circ}$ 9.057, de 25 de maio de 2017. Regulamenta o art. 80 da Lei $\mathrm{n}^{\circ}$ 9.394, de 20 de dezembro de 1996, que estabelece as diretrizes e bases da educação nacional. Brasília, 1996. Disponível em http://www.planalto.gov.br/ccivil_03/_ato2015-2018/2017/decreto/d9057 Acesso em 2 de março de 2021

BRASIL. Emenda Constitucional no 59 de 11 de novembro de 2009. Brasília, 2009. Disponível em http://www.planalto.gov.br/ccivil_03/constituicao/emendas/emc/emc59.htm Acesso em 2 de março de 2021

BRASIL, CNE/CP. Parecer CNE/CP n 5/2020, aprovado em 28 de abril de 2020 - Reorganização do Calendário Escolar e da possibilidade de cômputo de atividades não presenciais para fins de cumprimento da carga horária mínima anual, em razão da Pandemia da COVID-19. Disponível em Parecer CNE/CP n ${ }^{\circ}$ 5/2020, aprovado em 28 de abril de 2020 - Reorganização do Calendário Escolar e da possibilidade de cômputo de atividades não presenciais para fins de cumprimento da carga horária mínima anual, em razão da Pandemia da COVID-19. Brasília, 2020 Disponível em http://portal.mec.gov.br/index.php?option=com docman\&view=download\&alias=145011-pcp00520\&category_slug=marco-2020-pdf\&Itemid=30192 Acesso em 2 de março de 2021

BRASIL. Constituição da República Federativa do Brasil de 1988. Brasília, 1988 Disponível em http://www.planalto.gov.br/ccivil 03/constituicao/constituicao.htm Acesso em 21 de fevereiro de 2021

CHARCZUK, Simone Bicca. Sustentar a Transferência no Ensino Remoto: docência em tempos de pandemia. Educação \& Realidade, Porto Alegre, UFRGS, v. 45, n. 4, e109145, 2020 Disponível em https://www.scielo.br/scielo.php?script=sci_arttext\&pid=S2175-

62362020000400206\&lng=en\&nrm=iso Acesso em 2 de fevereiro de 2021

CHRISPINO, Álvaro \& CHRISPINO, Raquel S. P. Políticas educacionais de redução da violência: mediação do conflito escolar. São Paulo: Biruta, 2002. Disponível para consulta parcial em https://issuu.com/editorabiruta/docs/amadores Acesso em 2 de março de 2021

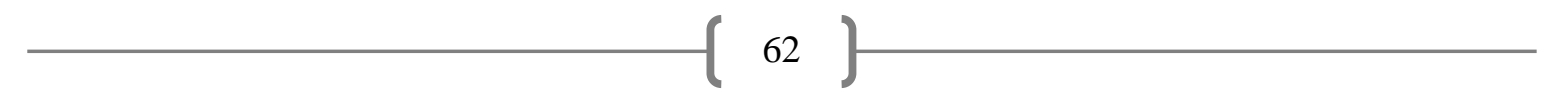

RIET- ISSN 2676-0355, Dourados, v. 2, n. 2, p. 38 a 63, jan./jun., 2021. 


\section{A escolarização pública e o imprevisto mais do que previsto}

GADOTTI, Moacir. Gestão democrática com participação popular: planejamento e organização da educação nacional. São Paulo: Instituto Paulo Freire, 2013.

JULIA, Dominique. A Cultura Escolar como Objeto Histórico. Revista Brasileira de História da Educação, Rio de Janeiro, v. 1, n. 1, p. 9-43, jan./jun. 2001. Disponível em:

http://periodicos.uem.br/ojs/index.php/rbhe/article/view/38749 Acesso em 19 janeiro de 2021

LIMA, Patrícia. Um ano de escolas fechadas: relatos de mães revelam fracasso do EAD na Capital. Porto Alegre, Matinal Reportagem, 2021 Disponível em https://www.matinaljornalismo.com.br/matinal/um-ano-ensinoremoto/?mc_cid=fcfaef8fd8\&mc_eid=f6d0e1f891 Acesso em 19 de março de 2021

PARKER, Richard. COVID 19 e a produção da ignorância. Revista RADIS, FIOCRUZ, Rio de Janeiro, 22 de março de 2021 Disponível em https://radis.ensp.fiocruz.br/index.php/home/opiniao/pos-tudo/covid-19-e-a-producao-daignorancia Acesso em 22 de março de 2021

SACRISTAN, José Gimeno. A educação obrigatória. Porto Alegre: Artmed, 2001.

SILVA, Maria das Graças Martins da \& VELOSO, Tereza Christina Mertens Aguiar. Acesso nas políticas da educação superior: dimensões e indicadores em questão. Avaliação, Campinas; Sorocaba, SP, v. 18, n. 3, p. 727-747, nov. 2013. Disponível em https://www.scielo.br/scielo.php?script=sci_arttext\&pid=S1414-40772013000300011 Acesso em 2 de março de 2021

TARDIF, Maurice; LESSARD, Claude. O trabalho docente: Elementos para uma teoria da docência como profissão das interações humanas. 5. ed. Petrópolis: Vozes, 2009.

UNESCO. Programa de Investigación y Prospectiva en Educación - Oficina Regional de Educación para América Latina y el Caribe. Seminario web: "Proteger y transformar lá educación para futuros compartidos y uma humanidad común". Santiago de Chile, 2020. Documento disponível em https://es.unesco.org/node/321417 Acesso em 2 de março de 2021.

VICTORIO FILHO, Aldo. Pesquisar o cotidiano é criar metodologias. Educação \& Sociedade, Campinas, v. 28, n. 98, p. 97-110, abril 2007 Disponível em: https://www.scielo.br/scielo.php?script=sci arttext\&pid=S0101$\underline{73302007000100006 \& \operatorname{lng}=e n \& n r m=i s o}$ Acesso em 7 de janeiro de 2021

63

RIET-ISSN 2676-0355, Dourados, v. 2, n. 2, p. 38 a 63, jan./jun., 2021. 